\title{
Characterization of Antigens in SSV Nonproducer Cells
}

\author{
H.-J. Thiel, T. Matthews, E. Broughton, A. Butchko, and D. Bolognesi
}

\section{A.Summary}

An autologous antiserum against simian sarcoma virus (SSV) nonproducer cells (SSV-NP cells) was characterized by radioimmunoprecipitation. It reacts specifically with two different molecules in SSV-NP cells, a SSV transformation-specific glycoprotein (SSV TrS-gp) and $\mathrm{p} 65$, which probably represents a modified gag-precursor.

\section{B. Introduction}

The SSV complex [SSV(SSAV)] contains a replication defective transforming virus (SSV) as well as an associated helper virus (SSAV). This mixture of transforming pseudotype SSV(SSAV) and helper virus was originally isolated from a spontaneous fibrosarcoma of a New World primate, the woolly monkey (Theilen et al. 1971). While SSAV has been quite well characterized (Aaronson et al. 1976; Benveniste et al. 1977; Deinhardt et al. 1978), relatively little is known about the replication defective transforming virus, SSV (Aaronson et al. 1975; Bergholz et al. 1977).

In an attempt to identify putative transformation specific information coded for by SSV, we isolated goat cells nonproductively transformed by SSV(SSV-NP) and inoculated these several times as live cells into the same goat from which they originated. The resulting hyperimmune serum (SSV-NP serum) was reacted in radioimmunoprecipitation against different transformed and nontransformed cell lines.

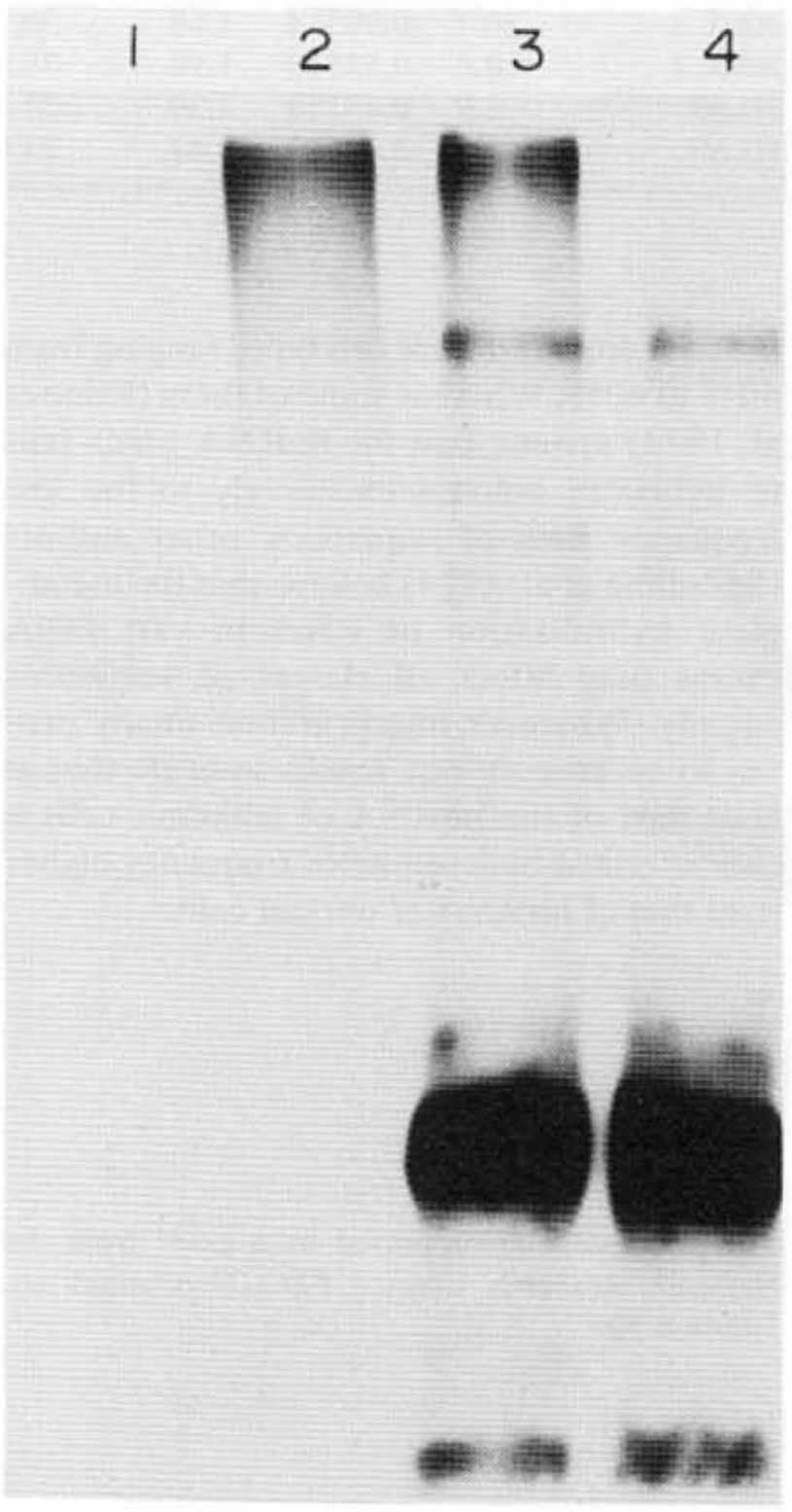

Fig. 1. Immunoprecipitation of SSV TrS-gp from tissue culture supernatants of NRK SSV-NP cells analyzed on a $5 \%$ SDS gel. Cells were labeled by a $7 \mathrm{~h}$ pulse followed by a $14 \mathrm{~h}$ chase: ${ }^{3} \mathrm{H}$-glucosamine label with preimmune serum (Lane 1) and SSV-NP serum (Lane 2). ${ }^{35} \mathrm{~S}$-cysteine label with SSV-NP serum (Lane 3) and preimmune serum (Lane 4) 


\section{Results}

\section{A Simian Sarcoma Virus Transformation- Specific Glycoprotein (SSV TrS-gp) in SSV-transformed cells}

After labeling SSV-NP cells with ${ }^{3} \mathrm{H}$-glucosamine and ${ }^{35} \mathrm{~S}$-cysteine using a $7 \mathrm{~h}$ pulse followed by a $14 \mathrm{~h}$ chase, the respective tissue culture supernatants were immunoprecipitated with SSV-NP serum (Fig. 1). The reactive molecule labels with glucosamine as well as cysteine and is therefore considered to represent a glycoprotein. On a 5\% SDS-gel it migrates only a few millimeters into the separating gel. In addition, tissue culture supernatants from a variety of cell lines were labeled with ${ }^{3} \mathrm{H}$-glucosamine and immunoprecipitated with SSV-NP serum. The ability of the immune serum to precipitate ${ }^{3} \mathrm{H}$-glucosamine label from tissue culture supernatants is depicted in Fig. 2 in comparison to preimmune serum. The following tissue culture supernatants and respective cell extracts did not react in RIP assays: SSAV-infected normal cells (autologous goat fibroblasts, NRK cells), Gib- bon ape lymphoma virus (GALV) infected cells, NRK cells transformed by Kirsten sarcoma virus (KiSV) or Moloney sarcoma virus (MoSV), mink cells transformed by the Snyder-Theilen strain of FeSV (MSTF), and transformed mouse cell lines (Moloney $\mathrm{S}^{+} \mathrm{L}^{-}$, Harvey sarcoma virus-NP, methylcholanthrene - MCA transformed cells). In contrast, a strongly positive RIP reaction was found with the tissue culture supernatant of SSV-transformed cells from three different species including goat (Go), rat (NRK), and marmoset (HF) cells. This reactivity was found only with the SSV-NP serum. Other sera tested, including anti-SSAV p30, gp70, and anti disrupted SSV(SSAV), did not specifically precipitate glucosamine label from supernatants of SSVtransformed NP cells. This apparent SSV specificity was further tested by passing the serum over an SSAV immunoadsorbent column. This step did not diminish its reactivity with the ${ }^{3} \mathrm{H}$-glucosamine labeled supernatant and the corresponding eluate was not reactive.

To characterize this molecule further, different radioactive compounds were used for metabolic labeling of SSV-NP cells. While the

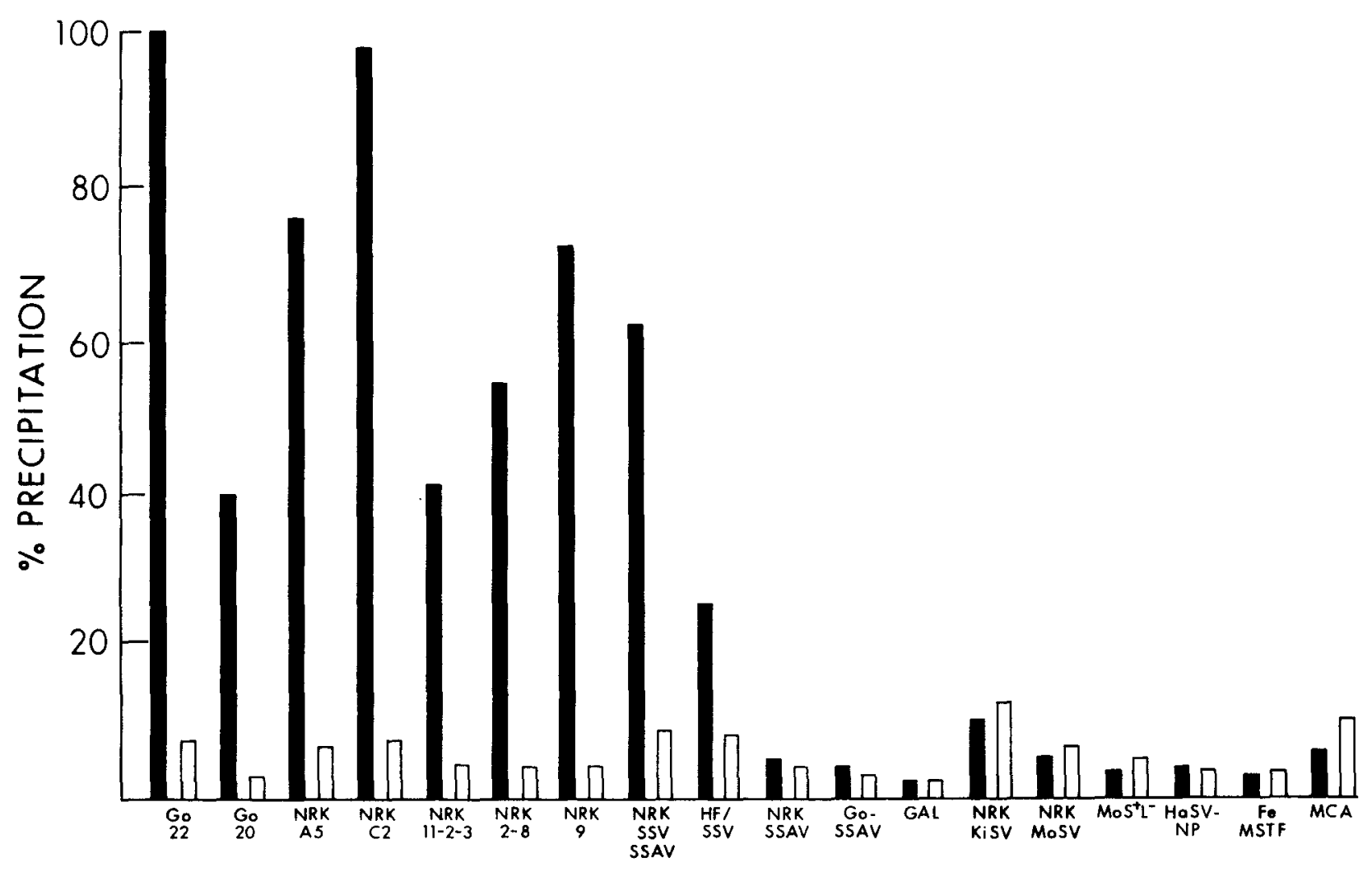

Fig. 2. Precipitated ${ }^{3} \mathrm{H}$-glucosamine label from tissue culture supernatants of different cell lines. Cells were labeled with ${ }^{3} \mathrm{H}$-glucosamine for a $7 \mathrm{~h}$ pulse followed by a $14 \mathrm{~h}$ chase. Each tissue culture supernatant was membrane filtered, extracted, and incubated with $1 \mu \mathrm{l}$ of serum. The $100 \%$ value is taken as the counts precipitated from goat clone 22 with SSV-NP serum. Clone 22 and 20 are goat SSV-NP clones; $A 5, C 2$, 11-2-3, 2-8 and 9 are NRK SSV-NP clones. solid bars, SSV-NP serum; open bars, preimmune goat serum 
SSV TrS-gp labeled effectively with ${ }^{3} \mathrm{H}$-galactose, it did not incorporate mannose, fucose, or phosphate. On the other hand, various protein precursors were only poorly incorporated. This material may thus represent a glycoprotein, but one belonging to a class in which the carbohydrate is the overwhelmingly dominant component. Because of the large complement of sugar, molecular size estimation of this material by SDS Polyacrylamide gel electrophoresis (PAGE) is difficult. We therefore examined the immune precipitate by gel filtration on a Sepharose $6 \mathrm{~B}$ column in the presence of $6 \mathrm{M}$ guanidine hydrochloride (not shown). Using cold FLV as standard, a single radioactive peak was found corresponding to the void volumn of the column. This indicates a molecular weight of at least 200,000 daltons.

\section{Precipitation of p65 from SSV-NP Cells}

The reactivity of the SSV-NP serum was examined through immunoprecipitation analyses of ${ }^{3} \mathrm{H}$-leucine labeled cell extracts. Figure 3 shows the reaction products with NRK SSV-NP cells (Lane 2) subsequent to analysis by SDS-PAGE. The only component which is specifically precipitated in comparison to the same cell extract reacted with the respective preimmune serum is a $65,000 \mathrm{~mol}$. wt. protein (p65). Further serological analysis of p65 indicated that this molecule possesses SSAV p12, p30, and probably p15 determinants. To determine the relationship of p65 to the SSAV gag-precursor, peptide analyses on these molecules were performed (Fig. 4) as described by Cleveland et al. (1976). While these maps show a considerable degree of homology, there is also at least one clear difference with each proteolytic enzyme tested.

\section{Discussion}

Our study was aimed at the preparation and characterization of an autologous antiserum against SSV-NP cells. Serum from this immunization was assayed by RIP against various SSV-NP cells and found to have specific reactivity for a 65,000 dalton polypeptide (p65) and a glycoprotein (SSV TrS-gp). Serological data and peptide analyses indicate that p65 probably represents a modified gag-precursor and not a gag-gene related transformation specific fusion protein.

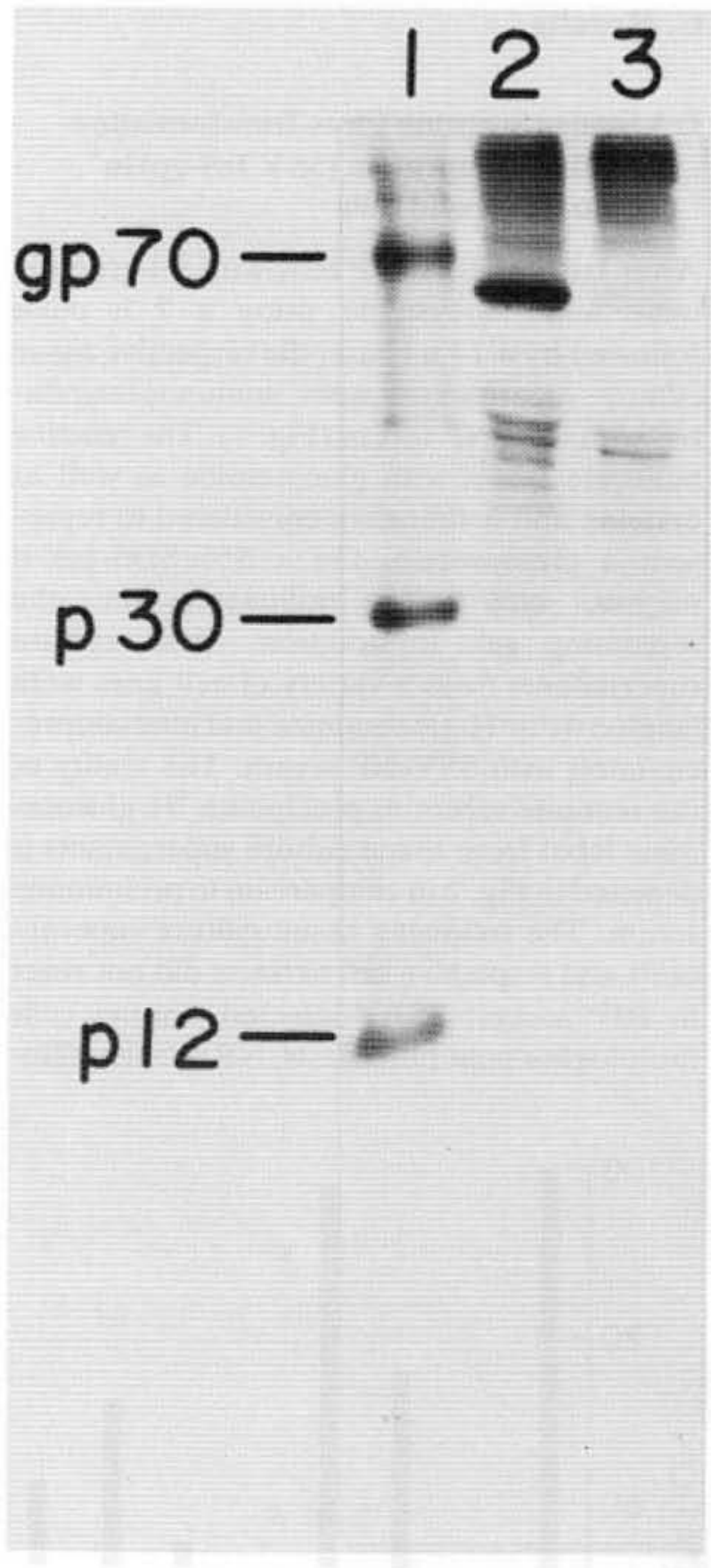

Fig. 3. Immunoprecipitation of p65 from NRK SSV-NP cells. Cells were pulse labeled with ${ }^{3} \mathrm{H}$-leucine for $7 \mathrm{~h}$, extracted, and $5 \times 10^{6} \mathrm{cpm}$ incubated with $1 \mu \mathrm{l}$ of serum. The molecular weight markers on this $12 \%$ slab gel are ${ }^{3} \mathrm{H}$-leucine labeled FLV structural proteins (Lane 1). SSV-NP cells with SSV-NP serum (Lane 2), and SSV-NP cells with preimmune goat serum (Lane 3)

The autologous goat serum recognizes an additional component which represents a rather unique glycoprotein (SSV TrS-gp). This molecule appears to be present in all SSV transformed cells tested, including goat, rat, and marmoset cells. It appears to be a large glycoprotein (at least 200,000 daltons) which 
possesses a fairly small protein backbone. Preliminary results indicate that the protein moiety is important for the integrity of the

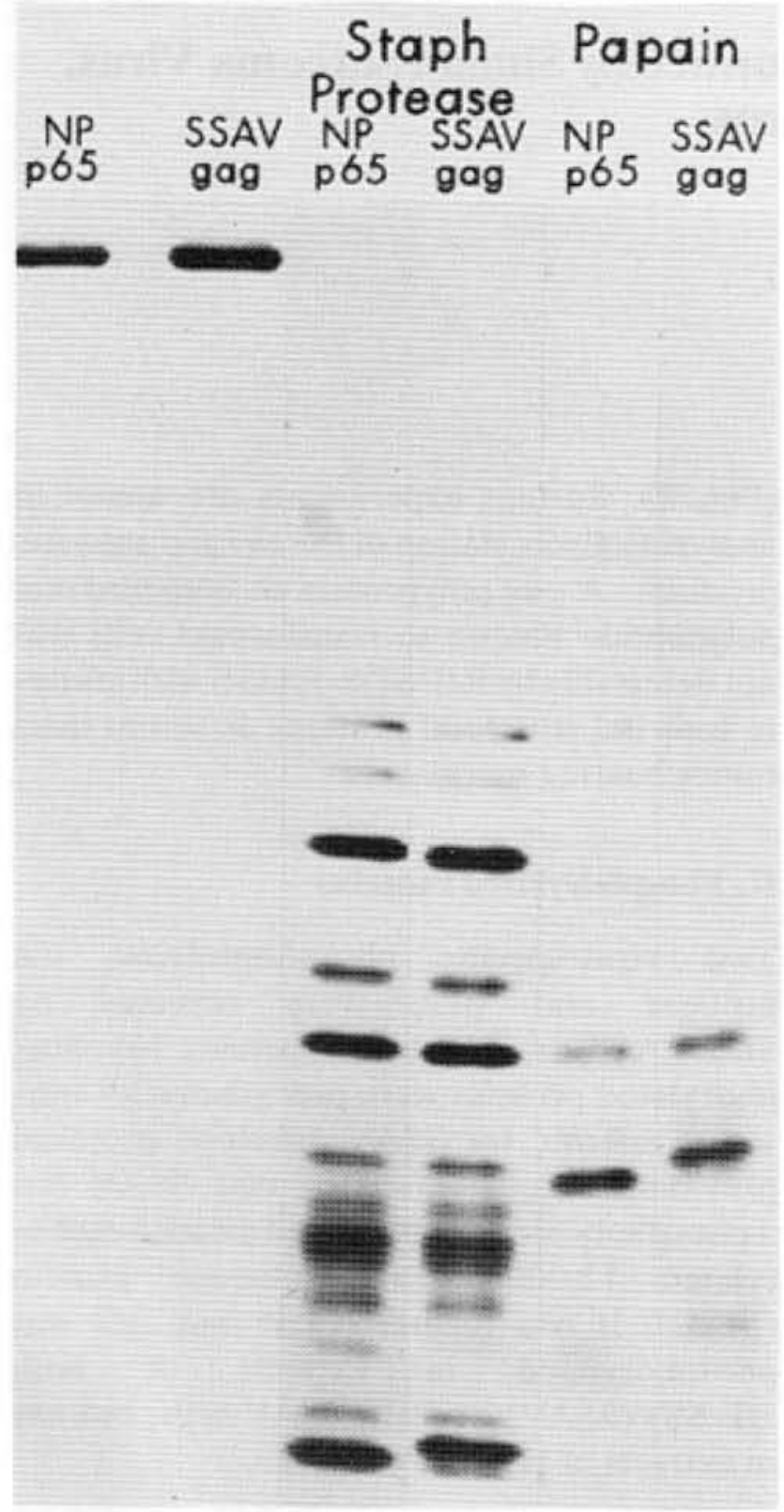

Fig. 4. After immune precipitation of ${ }^{3} \mathrm{H}$-leucine labeled p65 from SSV-NP cells and the gag-precursor from SSAV infected cells, the precipitates were electrophoresed on a preparative SDS gel and the respective bands cut from the gel. The slices were applied to a second SDS gel (15\%) and electrophoresed in the presence of either no enzyme, Staphylococcus aureus protease $(5 \mu \mathrm{g})$, or papain $(40 \mathrm{ng})$ as described (Cleveland et al. 1976) molecule on a $5 \%$ SDS gel as well as for its antigenicity (unpublished).

The SSV TrS-gp is probably coded for by SSV, because it was demonstrated in cells from three different species transformed by SSV and not by other transforming viruses. Our studies indicate that the SSV TrS-gp is easily shed or secreted by the transformed cell, and since the goat was immunized with live autologous transformed cells, the SSV TrS-gp might serve as an important target antigen for tumor cell recognition in vivo. Elucidation of the role of this glycoprotein in transformation by SSV awaits its purification and characterization.

\section{References}

Aaronson SA, Stephenson, JR, Hino S, Tronick SR (1975) Differential expression of helper viral structural polypeptides in cells transformed by clonal isolates of woolly monkey sarcoma virus. J Virol 16:1117-1123 - Aaronson SA, Stephenson JR, Tronick SR, Hino S (1976) Immunological analysis of structural polypeptides of woolly monkey - gibbon ape type-C viruses. In: Clemmesen J, Yohn DS (eds) Comparative leukemia research, vol 43. Karger, Basel, pp 102-109 - Benveniste RE, Callahan R, Sherr CJ, Chapman V, Todaro GJ (1977) Two distinct endogenous type $\mathrm{C}$ viruses isolated from the Asian rodent Mus cervicolor: Conservation of virogene sequences in related rodent species. J Virol 21:849-862 - Bergholz CM, Wolfe LG, Deinhardt F (1977) Establishment of simian sarcoma virus, type 1 (SSV-1)-transformed non-producer marmoset cell lines. Int J Cancer 20:104-111 - Cleveland DW, Fischer SG Kirschner MW, Laemmli UK (1976) Peptide mapping by limited proteolysis in sodium dodecyl sulfate and analysis by gel electrophoresis. J Biol Chem 252:1102-1106-Deinhardt F, Bergholz C, Hunsmann G, Schneider J, Thiel HJ, Beug H, Schäfer W (1978) Studies of simian sarcoma and simian sarcoma-associated virus. I Analysis of viral structural proteins, and preparation and characterization of antiserum specific for viral envelope components. $Z$ Naturforsch [C] 33:969-980 - Theilen GH, Gould D, Fowler M, Dungworth DL (1971) C-type virus in tumor tissue of a woolly monkey (Lagothrix spp.) with fibrosarcoma. J Natl Cancer Inst 47:881-889 